Rev. Chil. Pediatr. 64 (1); 22-25, 1993

\title{
Meningitis bacteriana: resultados clínicos
}

\author{
Pamela Barraza C. ${ }^{1}$, Santiago Topelberg V. ${ }^{2}$; Rosanna Lagos Z. ${ }^{2}$
}

\section{Outcome of acute bacterial meningitis}

In order to assess the current experience in the managentent of patients wilh ocule baclerial meningitis at a university affiliated melrcpolitan children's hospilal from Sanliogo. Chile. the medical iecords of all 175 patienis discharged with this diagnosis from january 1989 throughout july 1890 were relrospectively reviewed. As compared to a previously reported experience in the same institution 11070 to 1974$)_{s}$ no differences were found regarding incidence roles and distribution of etiological ogents. However monality rale decreased from 22,5 ro $9,7 \% ; 0 R=2,75 ; 0<0,0021$ and the identificalion rote of cousolive polhogens improved by $11 \%$.

[Key wordst boclerial meningitis.]

Aunque la meningitis aguda bacteriana del niño continúa siendo de gravedad indiscutible, su pronóstico parece haber mejorado en forma significativa. En las tres últimas décadas, las publicaciones extranjeras reflejan reducciones de hasta $20 \%$ en las tasas de mortalidad ${ }^{1}$, que no parecen acompaflarse de incrementos comparables en la frecuencia de secuelas ${ }^{2-5}$.

1. Departamento de Pediatría, División Ciencjas Médicas Norte, Facultad de Medicins, Universidad de Chile.

2. Servicio de Pediatrix, Hospital Roberto del Río, Servicio de Salud Metropolitano Norte.
El Hospital Roberto del Río atiende una cifra considerable de pacientes con meningitis aguda bacteriana, provenienles del área norte de Santiago y de las regiones III y IV, a las que sirve como centro de referencia. El promedjo anual de egresos con este diagnóstico (46 para los últimos cinco años), permite reunir series clínicas amplias en períodos relativamente breves. Puesto que la última evaluación de la experiencia en este centro fue publicada en 1978, parecía oportuno actualizar la información relativa $a$ aspectos epidemiológicos y pronóstico de la enfemedad. en base a una revisión de los casos más recientes. Paralelamente, quisimos comparar los datos ac- 
tuales con los de nuestra experiencia pasada y averiguar si esta casuística reproduce las tendencias favorables observadas en el extranjero.

\section{Material y Método}

Se revisaron las fichas clínicas de los niños mayores de 28 días egresados del Hospilal Roberto del Río con diagnóstico de meningitis aguda bacteriana, en el período comprendido entre enero de 1987 y julio de 1990. La pesquisa de casos fue realizada desde los registros de los libros de egreso de las unidades de infecciosos y cuidados especiales. Todos los pacientes incluidos en la revisión (175), tenían manifestaciones clínicas y alteraciones citoquímicas del líquido cefalorraquídeo compatibles con meningitis aguda bacteriana. La información extraida de las fichas incluyó las siguientes variables: identificación, fecha de ingreso, cdad, sexo, agente etiológico, técnica de diagnóstico bacteriológico y estado al alta. La información fue precodificada, registrada en protocolos individual cs y procesada en un microcomputador. Los datos relativos a documentación etiológica, mortalidad y secuelas fueron comparados con los descritos en una publicación previa del mismo hospital, correspondiente a una serie similar que abarcaba los casos del periodo enero de 1970 a diciembre de 19744 . Las comparaciones fueron hechas mediante cálculos de proporciones y riesgo relativo.

\section{Resultados}

De los 175 pacientes incluidos en la revisión, 105 correspondian a niños provenientes del área norte de Santiago; de acuerdo a las cifras poblacionales del INE, la incidencia anual de meningitis aguda bacteriana en el período estudiado fue de $16 \times 10^{5}$ menores de 15 años. No se observaron variaciones estacionales. Setenta por ciento ( $70 \%)$ de los casos ocurrieron en menores de un año. Aunque en la muestra general el predominio de los varones sobrc las niñas $(1,5: 1)$ no fue significativo, el análisis por grupos de cdad (tabla 1) evidenció un claro incremento de los hombres en la categoría de mayores de 5 afios en proporción $5: 1$ y tasa de probabilidad de ocurrencia $(O R=$ "Odds ratio") de 3,8.

En todos los casos revisados la investigación etiológica había íncluido al menos dos hemocultivos, cultivo y tinción de Gram de líquido cefalorraquídeo; el estudio de aglutinación directa de particulas de látex sc practicó en forma irregular (dependiendo de la disponibilidad del reactivo), a partir de 1987. El cultivo de líquido cefalorraquidco fue positivo en 135 pacientes, 61 de los cuales tenían además un hemocultivo positivo. En tres casos la etiología fue documentada sólo con hemocultivo. Las pruebas de aglutinación de látex fueron los únicos documentos etiológicos en scis pacientes (todos con infección por Haemophilus influenzae tipo b. Por otra parte, la tiación de Gram permitió sospechar la etiología en cuatro pacientes, en los cuales los demás estudios resultaron negativos. En comparación al periodo 70 a 74 , la documentación etiologica aumentó en $1 \%$ (tabla 2). Los agentes etiológicos se presentaron en la siguiente distribución de frecuencias: Haemophilus infuenzae tipo b, 63 casos (36\%); Streptococcus pnetumoniae, 45 ca$\operatorname{sos}(25,7 \%) ;$ Neisseria meningitidis, 38 casos $(21,7 \%)$. En veintitrés pacientes no se logró identificar el agente etiológico $(13,1 \%)$ y en 4

Tabla 1

Distribución de 175 casos de meningitis bacteriana según sexo y edad

\begin{tabular}{|c|c|c|c|c|c|c|c|c|}
\hline & \multicolumn{2}{|c|}{ Varones } & \multicolumn{2}{|c|}{ Mujeres } & \multirow[t]{2}{*}{$\%$} & \multicolumn{3}{|c|}{ IC $95 \%$} \\
\hline & $n$ & $\%$ & $n$ & $\%$ & & & & \\
\hline $\begin{array}{l}1 \text { a } 3 \text { meses } \\
>3 \text { meses-1 año } \\
>1 \text { año-5 años } \\
>5 \text { años }\end{array}$ & $\begin{array}{l}12 \\
46 \\
24 \\
25\end{array}$ & $\begin{array}{l}50,0 \\
52,9 \\
54,5 \\
83,3^{*}\end{array}$ & $\begin{array}{r}12 \\
31 \\
20 \\
5\end{array}$ & $\begin{array}{l}50,0 \\
47,1 \\
45,5 \\
16,7^{*}\end{array}$ & $\begin{array}{l}13,7 \\
44,0 \\
25,1 \\
17,1\end{array}$ & $\begin{array}{r}8,6 \\
37,0 \\
18,7 \\
11.5\end{array}$ & $\begin{array}{l}- \\
- \\
-\end{array}$ & $\begin{array}{l}18,2 \\
51,0 \\
31,5 \\
22,7\end{array}$ \\
\hline
\end{tabular}

OR $=3,8 ; \quad$ IC $95 \%=1,3-12,2 ; \quad p<0,01$.

OR : "Odds ratio" = tasa de probabilidad de ocurrencia. 
Tab]a 2

Frecuencia de documentación etiológica en meningitis bacteriana aguda, en dos períodos: $1970-1974$ vs $1987-1990$

\begin{tabular}{ccccc} 
& \multicolumn{2}{c}{$\begin{array}{c}\text { Con jdentificaction } \\
\mathbf{n}\end{array}$} & Total & IC det 95\% \\
\hline $1970-74$ & 113 & 66,9 & 169 & $59,9-74,0$ \\
$1987+90$ & 137 & 78,0 & 175 & $71,9-84,1$ \\
\hline
\end{tabular}

$\mathrm{P}=0,029$.

Tabla 3

Frecuencia de secuelas y muerte según etiología y edad en 175 pacientes con meningitis bacteriana aguda

\begin{tabular}{llccc} 
& $\begin{array}{c}\text { < de } 3 \text { meses } \\
\text { secuelas o muerte } \\
\text { sí }\end{array}$ & $\begin{array}{c}\text { no de } 3 \text { meses } \\
\text { secuelas o muerte } \\
\text { ní }\end{array}$ & no \\
\hline $\begin{array}{l}\text { Streptococcus } \\
\text { pnemoniae }\end{array}$ & 5 & 3 & 11 & $26^{*}$ \\
$\begin{array}{l}\text { Haemophilus } \\
\text { influenzae }\end{array}$ & 0 & 5 & 12 & $46^{* *}$ \\
\hline
\end{tabular}

* $: \mathrm{OR}=3,90$

** : $\mathrm{OR}=0,33$

OR : "Odds ratio" = tasa de probahilidad de ocumencia.

casos se encontró un patógeno poco habitual: Listeria monocytogenes (n:1), Streptococcus agalactiae -o grupo B- (n:2) y Streptococcus pyogenes $\rightarrow$ grupo $\mathrm{A}-(\mathrm{n}: 1)$, en 1,2 y 1 caso. respectivamente. Además, un pacientc sultió infección por Klebsiella pneumoniae, secundaria a traumatismo encefalocraneano y en otro, portador de tetralogia de Fallot, la meningitis fue causada por Streptococcus viridans.

Al momento del alta, $139(79,4 \%)$ de los pacientes se encontraban sin secuelas clínicamente cvidentes, diez y nueve $(10,8 \%)$, tenían algún trastorno neurológico atribuible a la meningitis (síndrome convulsivo, daño cercbral severo, déficit motor o hidrocefalia), y siete habían fallecido por complicaciones precoces directamente relacionadas con la enfermedad $(9,7 \%)$. Aunque los riesgos de muente y secuelas no mostraron relación con la etiología, los pacientes menores de tres meses con infección neu- mocócica, mostraron un riesgo significativamente más alto de estas complicaciones, al compararios con los nínos de la misma edad, infectados por otros agentes. En esta serie, el riesgo de morir disminuyó cerca de tres veces con respecto a la experiencia publicada previamente (tabla 4).

\section{Comentario}

La revisión expuesta ofrece una visión actualizada de los aspectos epidemiológicos y de pro. nóstico más relevantes de la meningitis aguda bacteriana, en la comunidad atendida por el Hospital Roberto del Río. En lo referente a incidencia y distribución etaria y etiológica, esta serie es parecida a la casuística previa y a lo informado en otras publicaciones ${ }^{6-8}$. Por otra parte, fue posible observar algunos cambios que reflejan progresos en la calidad de la atención médica entregada a los niños con meningitis bacteriana. Entre ellos destaca el incremento de casos con documentación etiológica y una clara reducción en la tasa de mortalidad. Pese a que en ambas series se aplicaron diferentes esquemas de terapia con antibióticos, la información disponible parece indicar que tales modificaciones en el tratamiento específico, no explicarían la mejoría del pronóstico vital de Ia meningitis aguda bacteriana; por ende, este cambio parece atribuible, con mayor probabjlidad, a la incorporación de recursos que ha permitido mejorar el tratamiento de apoyo y el mancjo de las complicaciones asociadas a la fase aguda de la enfermedad. Considerando las limitaciones que aún afectan a nuestro hospital, es digno de destacar que las actuales cifras de mortalidad sean del todo semejantes a las repor-

\section{Tabla 4}

Letalidad por meningitis bacteriana aguda en dos períodos: $1970-1974$ vs $1987-1990$

\begin{tabular}{lcccc} 
& \multicolumn{4}{c}{$\begin{array}{c}\text { Total fallecidos } \\
\%\end{array}$} \\
\hline $1970-74$ & 169 & 38 & 22,5 & $16,2-28,8$ \\
$1987-90$ & 175 & 17 & 9,7 & $5,3-14,1$ \\
\hline
\end{tabular}

$\mathrm{OR}=2,75 ; \quad$ IC $95 \%=1,4-5,3 ; \quad \mathrm{p}<0,002$.

OR : "Odds ratio" $=$ tasa de probabilidad de ocurrencia. 
tadas en centros extranjeros de elevado nivel tecnológico ${ }^{4,5,7}$. Esta revisión dejó en evidencia que hay aún falencias importantes en el seguimiento y la pesquisa de secuelas neurológicas como sordera, trastornos del aprendizaje o alteraciones conductuales que deberían ser resueltas.

\section{Resumen}

Con el objeto de revisar la experiencia más reciente con la atención de pacientes con meningitis aguda bacteriana en un hospital metropolitano para niños, se revisaron las fichas clínicas de los niños mayores de un mes egresados con esle diagnóstico desde el $1^{2}$ de enero de 1987 al 31 de julio de 1990. Se hicieron algunas comparaciones sobre ctiología, letalidad y secuelas con un informe previo, del mismo hospital, correspondiente a los afos 1970 a 1974. La serie actual estuvo constituida por 175 enfermos. En $137(78 \%)$ se logro identificar el agente causal, que con mayor frecuencia fue Haemophilus influenzae tipo b (36\%), seguido de Streptococcus pnesmoniae $(25,7 \%)$ y Neisseria meningitidis $(21,7 \%)$, distribución que no difirió de la encontrada en este mismo centro, en el período 1970 a 1974. La mortalidad en la serie más reciente fue $9,7 \%$ y la frecuencia de secuelas neurologicas graves alcanzó a $10.8 \%$; en comparación a la experiencia previa, el riesgo de morir disminuyó
2,75 veces y la identificación del agente bacteriano causante mejoró en $11 \%$.

(Palabras clave: meningitis bacteriana.)

\section{Agradecimientos}

Al Dr. Patricio Herrera L., por su valiosa colaboración en el análisis estadístico de este trabajo.

\section{Referencias}

1. Smith EJ: Purulent meniogitis in infants and children. I Pediatr 1954; 45: 425-436.

2. Guerrero J, Donoso E, Dubownas F: Meningitis purulenta. Rev Chil Pediair 1988; 59: 170-173.

3. Sande MA, Scheld $\boldsymbol{M W}$, McCraken Gll et al,: Pathophysiology of bacterial meningitis. Implications for new management strategies. Pediatr Infect Dis J 1987; 6: 1145-1171.

4. Sande MA. Scheld $M W$, McCraken GH et at.: Pathophysiology of bacterial meningitis. Summary of a work shop. Pediate Infec Dis J 1989; 8: 899-933.

5. Klein JO, Feigin RD, McCraken GH: Report of the task force on diagnosis and management of meningitis. Pediatrics 1986; 78 (Supl.): 959-982.

6. Topelberg S, Hetrera P, Manterola A, Anibas R, Rotón $R$ : Algunos aspectos clínicos de la Meningitis puntenta en el niño. Pediatria (Santiago) 1978: $21: 111-117$.

7. Puga $T$, Ruvinski $R$ : Meningitis bacteriana en Me neghello J. y cols. Pediatría 4" ed. Santiago: Public. Tecnicas Mediterraneo. 1991: 592-605.

8. Feigin $R$ : Bacterial Meningitis beyond the neonaltal Period. In: Feigin R. and Cherry ID. Text Book of Pediatric Infectious Diseasses. Philadelphia: WB Saunders Co. 1981: 293-308. 